\title{
Post-Keynesian and Kaleckian thoughts on ecological macroeconomics
}

\author{
Giuseppe Fontana and Malcolm Sawyer \\ University of Leeds, UK
}

This paper outlines an approach to ecological macroeconomics based on post-Keynesian and Kaleckian ideas. It views growth as demand-driven through investment, and focuses on the conflicts between that demand-driven growth rate, the growth of the effective labour force and the 'nature constrained' rate of growth. The paper argues that there will not be 'market forces' which will address those conflicts, and specifically to bring growth to an environmentally sustainable growth rate. The policy agenda which is suggested is wide ranging and it calls for appropriate fiscal policy and budget deficits.

Keywords: ecological economics, sustainability, post-Keynesian, Kaleckian, demand-led growth

JEL codes: $Q 57, E 12, E 51$

\section{INTRODUCTION}

Post-Keynesian and Kaleckian macroeconomics have focused on the role of aggregate demand in the determination of the level of economic activity in a monetary production economy, and viewed securing high levels of demand in order to generate low levels of unemployment to be important. These macroeconomics analyses have tended to focus on the expansion of demand, where economic activity is within the constraints of supply. Building on this framework, this paper seeks to explore some issues arising from ecological and environmental limitations to the pursuit of economic growth. In this regard there are two basic themes. First, in a demand-driven economy there are consequences for profits, budget deficits and current account balance arising from slower growth. Second, the (growth of) supply constraints and the interdependence of the evolution of aggregate supply and demand have to be brought together in order to provide insights into policies to address environmental and ecological constraints.

\section{AN OUTLINE OF THE THEORETICAL FRAMEWORK ${ }^{1}$}

One of the main tenets of post-Keynesian and Kaleckian macroeconomics is that the growth rate of an economy is driven by the growth of the aggregate demand for goods and services, which in turn is mostly affected by changes in the level of investment (in fixed capital formation). Within this theoretical framework, then, a central issue

1. This theoretical framework is developed in Fontana/Sawyer (2012). 
becomes whether the growth of aggregate demand is sufficient to match the growth of the labour supply, and hence whether or not the economy can avoid an equilibrium underemployment of labour. Supply bottlenecks, capacity constraints, imbalances and 'market failure' within the economy place constraints on growth and full employment of labour, as within the broad structuralist approach within post-Keynesian macroeconomics. $^{2}$

The analysis presented in this paper maintains this simple theoretical framework, but it adds to it through consideration of ecological and supply constraints. The growth of the economy is perceived as driven by the growth of aggregate demand, and can be constrained by the growth in the labour supply in an economy approaching full employment. The growth of the economy is now viewed as eventually restricted by the growth of use of the ecological system and the environment, or what many would label the use of 'natural capital', and which can be viewed in terms of the 'ecological footprint', namely 'the area of productive land and water ecosystems required to produce the resources that the population consumes and assimilate the wastes that the population produces, wherever on Earth the land and water is located' (Wackernagel/Rees 1996, as reported by Sustainable Scale Project 2013). The working assumption in this paper is that the growth of aggregate demand tends to be greater than the sustainable growth of the ecological footprint, and hence a major challenge is to constrain the growth of demand in order to meet sustainability concerns.

The resources used in or up in the production process can be categorised under three headings, each with their own characteristics.

1. Physical (or manufactured) capital: A significant element in the post-Keynesian approach is that the amount of investment undertaken in the economy affects both the aggregate demand and the aggregate supply of goods and services. In other words, investments are the main factors affecting changes in the aggregate demand of goods and services, while also contributing to create the supply capacity of the economy. Therefore, the capital stock, $K$, is associated to capacity output, $Y_{c}$, by the following relationship: $Y_{c}=K / v$ where $v$ is the capital-capacity output ratio.

2. Labour: The capacity of people to work, $N$, is measured in 'efficiency units' of person hours, and is represented as $N=q . L$ where $q$ is a measure of labour productivity and $L$ is person hours. Labour productivity, $q$, is affected by several factors, including technical progress, skill formation and training activities. In line with post-Keynesian and Kaleckian macroeconomics, this paper assumes that aggregate demand and capital formation are able to affect the above factors and hence labour productivity. The growth of person hours in 'efficiency units' terms available for (paid) employment, $L$ (in effect the supply of labour), clearly depends on growth of productivity, changes in the hours of work, changes in participation rates and population growth. Actual employment depends on the level of demand, and is taken to be proportional to output (that is, a fixed coefficient regime is assumed). The supply of labour is influenced by the pace of demand with, for example, productivity being influenced by demand (Verdoorn Law type effects), and with participation rates and hours worked also responding to demand (as well as to changes in social norms).

2. For some overviews on the structuralist approach see, for example, Chenery (1975), Dutt (1999), Taylor (2004). 
3. The use of the natural environment: It may be labelled 'natural capital', but this is a complex category of capital which is used, not without controversy. ${ }^{3}$ The terminology used in this paper is that of the 'ecological footprint'. The Global Footprint Network states that, on the demand side, ecological footprint is:

how much land and water area a human population uses to provide all it takes from nature. This includes the areas for producing the resource it consumes, the space for accommodating its buildings and roads, and the ecosystems for absorbing its waste emissions such as carbon dioxide. These calculations account for each year's prevailing technology, as productivity and technological efficiency change from year to year. The accounting system also tracks the supply of nature: it documents how much biologically productive area is available to provide these services (biocapacity). (Global Footprint Network 2013)

The growth of the ecological footprint (on the demand side) is viewed as related to the growth of actual output as $g_{e f}=f\left(g_{y}\right)$. The function can change over time through several factors, including technical change, variations in the energy intensity of production, and the composition of output and consumption. Biocapacity cannot grow at a sustained rate of more than $g_{e f} *$ (which may be zero or negative).

The nature of the relationship between the resources used and the level of production is highly significant in this regard. Following much of the post-Keynesian tradition, the production relationship is treated as akin to a 'fixed factor proportions' production function, with the clear implication that there is no direct substitutability between the resources used. Thus, a 'fixed factor proportions' production function approach rejects the possibility of continuous substitution, a standard feature of neoclassical production functions such as the Cobb-Douglas function. In neoclassical production functions, there is perfect substitutability among inputs such that the level of output is maintained constant as long as the reduction in the service of an input is compensated by the use of other inputs. Indeed, in the Cobb-Douglas (and many other) production functions, one input can be reduced to infinitesimally small amounts and output maintained, provided that other inputs are increased. Since capital stock can be added to, the adoption of such production functions implies that the use of, for example, oil as an input can be reduced to close to zero provided there is a sufficient increase in the capital stock. Furthermore, when it is assumed continuous substitution between the resources used, it is generally taken that firms will make their choice among alternative use of available resources on the basis of profit calculations and relative prices, and that the use of scarce resources reduced by ensuring an appropriate price is placed on the use. By contrast, in this paper there is no direct influence of relative prices on resource use, though the relationship between resource use and output can change over time, notably through technical change. In turn, the ways in which research and development is pursued and implemented may be influenced by prices, costs and perceived profitability; that is, for example, research seeking ways of developing solar energy usage can be influenced by subsidies.

This paper treats the relationship between capital stock and capacity output as constant with a capital-capacity output ratio of $v$. Similarly, it is assumed that the use of 'efficiency' units of labour in person-hour terms is in a constant relationship with actual output. However, since the analysis below treats technical progress as a

3. Burkett (2003) presents an analysis of different views of 'natural capital' in ecological economics and related diverse conceptions of 'sustainable development'. 
labour-enhancing process, that along with skills and training means that, via increases in labour productivity $q$, the use of actual labour declines relative to output. This implies that skills, training and technical progress lead to a declining labour-output ratio. Finally, the relationship between the growth of the 'ecological footprint' and the growth of output is treated as subject to modifications through technical change, which can be enhanced through well-directed research and development, and through changes in the composition of output (for example, towards services and away from material production).

The approach used in this paper, including the adoption of a 'fixed factor proportions' production function, is consistent with a standard assumption in ecological economics, namely that physical (or manufactured) capital and environmental (or 'natural') capital are complementary rather than substitutes.

Economic production is a work process that uses energy to transform materials into goods and services; ... producing a manufactured-capital substitute requires input of natural capital and ... the multi-functional nature of ecosystems in sustaining socioeconomic development makes it difficult to substitute their life-support with manufactured-capital. (Ekins et al. 2003: 160)

In other words, the approach used in this paper adopts the 'strong sustainability' hypothesis (Ekins et al. 2003). According to it, there is very limited possibility of substitution between physical (or manufactured) capital and labour (or human capital) on one side, and the use of natural environment on the other side. The post-Keynesian macroeconomic perspective suggested in this paper also supports an endogenous money approach, though for reasons of space the discussion of monetary issues is left in the background. However, it is worthwhile mentioning that the driving force of the model - that is, investment expenditure - can only be undertaken if finance is available. In this regard, the central bank and banks determine the price and quantity of credit necessary to finance the production process and hence the quantity and structure of investment (Fontana 2010). A significant lever on the structure of investment, and particularly the 'greenness' of investment, could therefore come from policies affecting the nature and destination of bank lending.

A post-Keynesian approach would also stress the roles of fundamental uncertainty and of path dependency in general, and these become particularly relevant when analysing environmental and ecological issues, in line with much of the ecological economics literature (Daly 1991; 1996). The macroeconomic approach below incorporates these features, though it may be more implicit than explicit. Path dependency is incorporated as the path of the economy is built up, period by period, resulting from investment (and many other) decisions, and does not take a neoclassical view that there is an equilibrium path for the economy which is in effect predetermined. Further, decisions on investment are not based on any notion of 'rational expectations' on an already defined future, but rather they are influenced by the state of 'animal spirits'.

\section{THE ROLE OF INVESTMENTS AND AGGREGATE DEMAND}

In a post-Keynesian/Kaleckian perspective, investment is strongly influenced by the rate of capacity utilisation (relative to some 'desired' rate of capacity utilisation), profitability (with profits seen as a source of internal funds and future profits as incentive for investment) and a range of factors including the state of 'animal spirits', the impact of technological opportunities, and credit conditions. The profit share has a positive 
effect on investment: as it increases, more internal funds are available to finance investment, ceteris paribus. Similarly, capacity utilisation has a positive effect on investment: as it increases, expected sales move towards the maximum productive capacity, which in turn stimulates investment. Optimistic animal spirits and relaxed credit conditions have also a positive effect on investment, ceteris paribus. It is important to note that there are many factors which will lead to investment shifting over time, and that those shifts lead to changes in investment and thereby in the path of the capital stock and the economy. There is also the influence of credit conditions on investment. This means that the structure of investment depends on the lending activity of banks and financial institutions as well as on the public policy regulating bank lending and financial activities. As a result, some forms of desired investment may not come into existence. Similarly, some groups of individuals may be favoured over others in terms of direct access to credit and/or differential interest rates.

Consumer expenditure is treated here as rather passive in the sense that it follows the path of wages and profits. In the context of ecological concerns, this may understate the materialistic drives behind consumption, and that lower growth necessarily involves lower growth of consumption. Savings are treated in terms of differential savings out of wages and out of profits.

Two rather simple but powerful conclusions can be derived from a model based on these propositions. First, from the well-known relationship of:

$$
G-T=S-I-N X,
$$

where $G$ is government expenditure, $T$ tax revenue, $S$ private savings, $I$ private investment and $N X$ net exports, a lower rate of growth and hence a lower level of investment would require some combination of larger budget deficit, lower savings or higher net exports, if capacity utilisation and employment rate are to be maintained. A working assumption of this paper is that ecological concerns will entail lower growth and lower investment. It is obviously not possible for each country to boost net exports, and hence the choice comes down to higher budget deficits or lower savings. In the face of ecological concerns, it becomes more imperative for countries to adopt relevant fiscal policies (that is, substantial budget deficits in most cases) and not seek to lock themselves into the pursuit of balanced budgets.

The second conclusion which can be drawn relates to the rate of profit. In a closed private sector economy, from the savings-investment equation, with differential savings out of wages $(W)$ and out of profits $(P)$ :

$$
I=s_{p} P+s_{w} W
$$

with investment treated as the driving force, the rate of profit would be given by:

$$
P / K=\left[g_{K}-\left(s_{w} u / v\right)\right] /\left[s_{p}-s_{w}\right],
$$

where $g_{K}$ is growth of capital stock equal to $I / K$, and $u$ is capacity utilisation and $v$ capital-output ratio (hence $u / v=Y / K$ ). The particular significance of this type of equation is the implication that a lower growth rate (of capital stock) will be associated with a lower rate of profit. Ecological constraints will lead to lower growth of output and the capital stock, thereby implying a lower rate of profit. The rate of profit would however be enhanced through lower savings and through a budget deficit when the model is extended to include government expenditure and tax revenue. 


\section{AGGREGATE DEMAND, AGGREGATE SUPPLY AND THE SUSTAINABLE GROWTH RATE}

The previous sections have maintained that three main resources are used in or up in the production process, namely physical capital, labour services and 'ecological footprint'. It follows that the interaction between aggregate demand and the growth rate of physical capital, labour services and 'ecological footprint' determines the equilibrium level of output and its growth rate. Furthermore, this paper has assumed that investments are both a component of aggregate demand and the main driver of aggregate supply through changes in the capital stock. Therefore, the growth rate of physical capital is the main determinant of the equilibrium level of output and its growth rate. Within this framework, there is then the question of how to reconcile the growth rate of labour services and 'ecological footprint' with the growth rate of physical capital. The relationship between the growth rate of labour services and the growth of demand and output will clearly set whether unemployment is rising or falling, and the difference between them would involve continuous changes in the unemployment rate. A high rate of growth of demand and capital stock relative to the sustainable 'ecological footprint' brings ecological problems.

If these problems have to be limited or eliminated altogether in the long run, then it is necessary to analyse the forces at play in the economy that may bring the growth rate of physical capital, labour services and 'ecological footprint' in line with each other.

Three growth rates of output are now identified. These are the growth rate which is demand-driven, the growth rate based on labour supply and the growth rate consistent with a sustainable 'ecological footprint'. These growth rates are in general different from each other, and this paper maintains that there are not adjustment processes which could be termed 'market forces' that would bring the three growth rates into alignment. In a sense, the question raised here is similar to that which has arisen before in growth theory, namely the adjustment of the 'warranted rate of growth' and the 'natural rate of growth' which the neoclassical growth model resolves through removal of an independent investment function and the substitution between labour and capital. In an approach where there is an independent (of savings) investment function and a fixed factor coefficient approach to the production function, a comparable adjustment process is not available. ${ }^{4}$ The approach below is to argue that there have to be governmental and social adjustment processes to ensure that the ecological sustainable growth rate is achieved.

The three identified growth rates are:

1. The growth of capital stock, which arises from the interactions of investment and savings. This is a demand-led growth rate (which is not unlike the 'warranted rate of growth' in the Harrod-Domar model setting). There is then a corresponding (and equal, since the capital-output ratio is treated as constant) growth of output, which is labelled $g_{1}$.

2. The growth of the labour resource in 'efficiency units', which would result in a growth of output, say $g_{2}$, consistent with a constant rate of employment. This is a supply-led growth rate based on the labour force. Since the analysis assumes a 'fixed factor proportions' production function, this means that the rate of

4. From a Kaldor (1955) perspective, an induced change in the distribution of income between wages and profits would change the warranted rate of growth, but not operating through labour-capital substitution. 
growth of output and of the growth of the labour force in 'efficiency units' would be equal.

3. The growth of output imposes a growth of the 'ecological footprint'. This paper postulates that there is a sustainable growth rate (possibly zero or negative) of the 'ecological footprint', which is labelled $g_{e f} *$. The rate of growth of output which would be consistent with that sustainable rate is labelled $g_{3}$, and would be given by $g_{3}=f^{-1}\left(g_{e f} *\right.$ (where the function $f$ is the one referred to above). This is a nature-led growth rate, and will be referred to below as the "ecological footprint' constrained rate of growth of output.

Figure 1 provides a representation of the growth of the capital stock, the labour resource in 'efficiency units', and the 'ecological footprint', and the embedded tension between the growths of output associated with them. In Figure 1, the growth rate of the capital stock (from the investment function, and the growth of demand) is taken as $g^{*}$ which would correspond to growth of output $g_{1}$. The growth of the labour resource is modelled as influenced by the growth of output (and demand): for example, labour productivity may be stimulated by the pace of demand, and movements into or out of the labour force similarly may be demand-influenced. The 'growth of labour force' line in Figure 1 reflects that; and the growth of the labour resource and the growth of output would be equal at point $\mathrm{B}$, and growth rate $g_{2}$. The growth rate $g_{3}$ is, as described above, the rate of growth of output consistent with a sustainable 'ecological footprint'. The growth rates $g_{1}$ and $g_{2}$ are taken as greater than $g_{3}$ : whilst in Figure $1 g_{1}$ is taken as greater than $g_{2}$, there is nothing in the discussion which depends on that.

In the analysis which is summarised by Figure 1, there would not be any automatic market forces which would bring these three different growths of output into alignment with each other. Overuse (or underuse) of the capital stock, the labour resource in 'efficiency units', or the 'ecological footprint', will not produce an automatic,

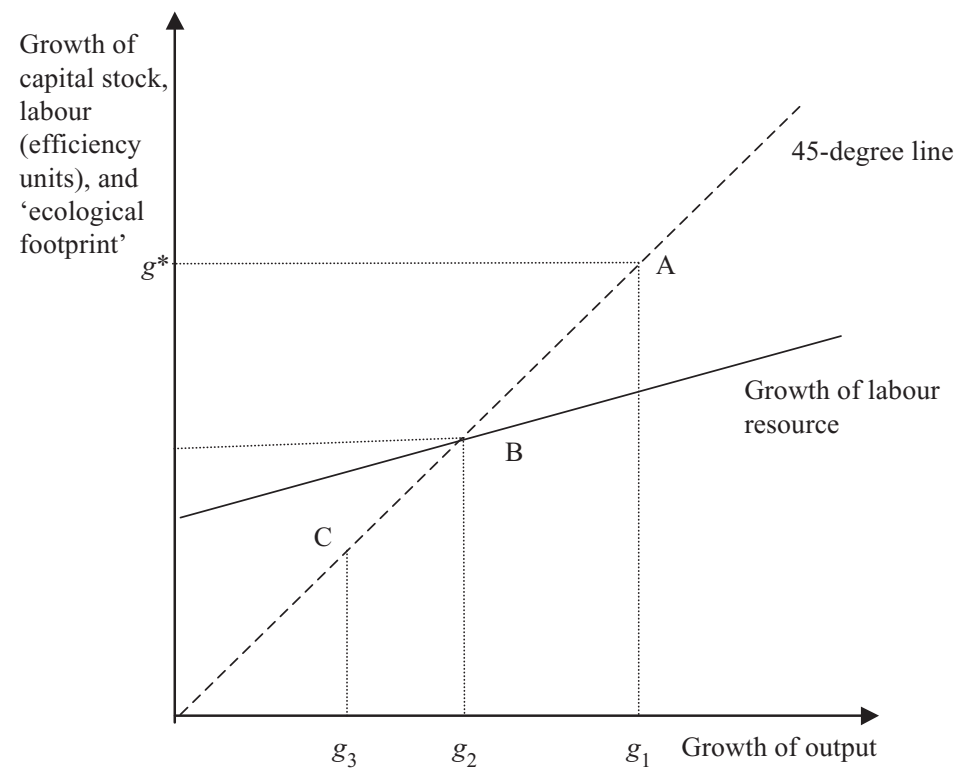

Figure 1 The growth of resources and the sustainable growth of output 
self-adjusting change in relative prices such that the overuse (or underuse), say, of 'ecological footprint' will be eliminated with an increase (decrease) in the use of capital stock or the labour resource in 'efficiency units'. This means that at least in the short run it cannot be excluded that the economy will experience severe environmental problems together with rising levels of unemployment (depending on the growth rate of labour as compared with actual growth) and idle capital stock (also depending on actual growth rate). In the long run, short of an ecological disaster, overuse of the 'ecological footprint' has to be contained, and possibly eliminated. Therefore this paper maintains that the long-run growth rate of output is nothing but the sustainable growth rate of output that is, the lowest output growth rate arising from the use of physical capital, labour services and 'ecological footprint'.

The actual growth rate of the economy would, this paper argues, be demand-driven and growing or declining employment rate would result, depending on the growth of the effective labour force. But the eventual constraints on the sustainable rate of growth come from the ecological footprint considerations. A failure of the demand-driven growth rate and the 'nature constrained' growth rate to come into line would spell disaster.

\section{POLICY IMPLICATIONS}

This section briefly suggests the overarching policy implications which appear to flow from a post-Keynesian/Kaleckian approach to ecological macroeconomics.

\subsection{Lack of self-adjusting market forces}

The first and major implication which can be drawn from the model sketched above is the paucity of self-adjusting market forces that serve to reconcile the three growth rates identified when the corresponding growth rates of output are different, and specifically the downward adjustment of growth rates to a sustainable rate. Government policies are likely to be a more effective force to influence the factors determining whether growth is sustainable, impacting on the growth rate of the 'ecological footprint' (relative to growth of output) and on growth of labour force. Changing social norms are also likely to have a major role to play. For example, government policies and social norms could be usefully used to modify the behaviour of banks, financial institutions and borrowers in a way to affect investments and consumption in the economy toward a more sustainable long-run perspective. Similarly, government policies and social norms could influence research and development activities or the use of labour force (that is, changing working hours, age of entry into and exit into the labour market) such that to bring the growth of the capital stock and the labour resource (in 'efficiency units') toward the long-run sustainable growth rate of output.

\subsection{Investment and aggregate demand}

In a post-Keynesian/Kaleckian spirit, investment plays a key role in the determination of the level of demand and the evolution of the capital stock. A lower rate of investment will be required in future as a lower ecological sustainable growth path is approached. As this paper has pointed out, adjustments to the fiscal position with larger budget deficits and a lower rate of savings will be required to accommodate the lower rate of investment without compromising the rate of employment. 
'Animal spirits', expectations on future growth and profitability are important drivers in investment decisions. Amongst those 'animal spirits' could be included perceptions on the growth of markets into which the firms are selling their output. It is possible that the perceptions of lower future growth through realisations of the environmental constraints could lead to lower 'animal spirits' and thereby lower investment. On these lines, investment would decline (and the rate of growth alongside it) through the decisions made by firms, and this could be viewed by some as a market adjustment process.

Within what is likely to be a lower rate of investment, the major challenge is to ensure that investment which is conducive to environmentally friendly production is funded. The market mechanisms cannot be relied upon to do this and this paper suggests that some direction of funding (by government) will be required, and this can be more readily accomplished through a bank-based financial system than a market-based system (see Pollin 1995 for a statement of this general argument). It may well require that a required proportion of lending by banks is directed towards 'green investment' (or at least to investment which is not environmentally unfriendly), and the establishment of publicly sponsored banks specifically designed to support such investments. From a post-Keynesian/Kaleckian analysis, the clear implication is to both lower the rate of investment and to change the structure of investment.

\subsection{Fundamental uncertainty and path dependency}

The development of a post-Keynesian/Kaleckian ecological macroeconomics, in line with much writing in ecological economics, would have to place more emphasis than has been apparent in this paper on two fundamental aspects of a post-Keynesian/Kaleckian approach, namely fundamental uncertainty and path dependency. In the modelling of, for example, investment decisions, it has to be recognised that there is not a predetermined path for the economy and that optimising decisions under full information are not possible (whether for reasons of lack of ability to optimise and recognition that since the future is yet to be discovered there cannot be full information on the future). It is, though, in the context of the 'ecological footprint', the relationship between growth of output and the footprint, the rate and nature of climate change and its impacts that fundamental uncertainty has its full impact.

In a post-Keynesian/Kaleckian approach, there is an inevitable path dependency in that, for example, the capital stock is built up from the path of investment, and the path of investment comes from a sequence of decisions being made (under conditions of fundamental uncertainty). ${ }^{5}$

\subsection{Productivity and technology}

Without seeking to engage in 'technological optimism', policies designed to foster research and development in the developments of 'green technologies' and other ways of reducing the 'ecological footprint' could offer significant benefits. This would require appropriate investment in environmental technology and new physical equipment to embody the technical change. In terms of the model above, this can be represented by seeking to influence the relationship between the 'ecological footprint' and output (summarised as $g_{e f}=f\left(g_{y}\right)$ ). It is rather easier to write down that relationship

5. For essays on the nature and role of path dependency, see Arestis/Sawyer (2009). 
than it will be to operationalise the idea, particularly in the face of fundamental uncertainty over the precise relationship and how it may be changed, not to mention the fundamental uncertainty surrounding the outcome of any research and development. At a general policy level, the implications follow from the well-known need for public sponsorship of research and development, particularly in the case of discrepancy between what may be considered as the social returns to research and development and the private returns, and the risk and uncertainty associated with research and development.

\subsection{Labour force and population}

The second growth rate identified in Figure 1 is based on the growth of the effective labour force. The reduction of that growth rate is a clear component of ensuring that overall growth of output is consistent with ecological sustainability. It is self-evident that many factors influence the growth of the effective labour force - productivity of personhours, changes in average working week, participation rates and population. A slowdown in the rate of growth of demand would (in line with Figure 1) lead to a slower growth of the growth of the effective labour force (in the post-Keynesian/Kaleckian approach) as a move down the 'growth of labour resource' line. However, in order to bring the growth of effective labour force into consistency with the 'ecological footprint' constraint, the equivalent of a shift in the line itself would be required. There would not appear to be 'market forces' which would reduce the growth of the effective labour force - that is, there do not appear to be changes in real wages driven by changes in the demand-andsupply balance which would lead to a lower growth rate.

For most industrialised countries where population growth rates are small (and in some cases negative), the major focus of action should be on the reduction of hours of work. The growth rate of labour productivity could also be slowed to reduce the growth of the effective workforce. This paper would not advocate that as a deliberate focus of policy, though would recognise the strong possibilities that the growth of labour productivity may well be slowing (for example, the lack of labour productivity growth in many industrialised countries in the past few years). The reduction of hours of work could come through a range of routes including (in the European Union context) working time directives, shortening of working life through later entry into and/or earlier exit from the work force. Rosnick (2013), for example, argues that

a significant reduction in climate change is possible by choosing a more European response to productivity gains rather than following a model more like that of the United States. By itself, a combination of shorter workweeks and additional vacation which reduces average annual hours by just 0.5 percent per year would very likely mitigate one-quarter to onehalf, if not more, of any warming which is not yet locked-in. (Rosnick 2013: 132)

In terms of the differences between the three growth rates identified in Figure 1, a 0.5 per cent per annum difference in annual hours worked would make a substantial contribution to closing the gap between $g_{2}$ and $g_{1}$.

The issue of population growth also needs to be raised. In the framework proposed in this paper, there is clearly a role for a slower growth of population in limiting the growth of the effective labour force. One element which does not feature in the framework is the consequence of the growth rates labelled $g_{1}$ and $g_{2}$ not adjusting to the nature-constrained growth rate, and forms of Malthusian mechanisms could come into play. This could come from the growth of output above the nature-constrained 
growth rate leading to environmental degradation, climatic change and agricultural failures which would feed back adversely on the growth of population. The scale of the difference between what is labelled as growth rates $g_{2}$ and $g_{3}$ (and also the sustainable level of population) is a matter of intense debate and widely differing forecasts, and yet the scale of the difference is crucial for policy.

\section{CONCLUDING COMMENTS}

The post-Keynesian/Kaleckian approach which has been sketched in this paper suggests a range of policy implications and conclusions. The first is that moving the growth of output to one which is ecologically sustainable requires major adjustments to the growth of the capital stock (and hence of investment) and to the growth of the effective labour force. Both will be required. The second is that there is a paucity of 'market forces' which would bring about such adjustments, and that public and social policy responses are required to, for example, change the structures of investment and research-and-development expenditures in directions which are environmentally friendly. The third is the need to develop policies to reduce the growth of the effective labour force through reductions in hours of work (whether on an annual basis or over lifetime through reduction of length of working life). Again, the lack of 'market forces' here requires public policies. The fourth is that a lower rate of investment would lead to a greater need for appropriate fiscal policy and budget deficits. The fifth is the need in the face of fundamental uncertainty and path dependency to adopt a precautionary approach to these policies - that is, to veer in the direction of lower growth. The overall implication of this paper is the need to address a wide range of complex and multifaceted policies in order to achieve a long-run sustainable growth rate.

\section{REFERENCES}

Arestis, P., Sawyer, M. (eds) (2009): Path Dependency and Macroeconomics, Basingstoke, UK: Palgrave Macmillan.

Burkett, P. (2003): Natural capital, ecological economics, and Marxism, in: International Papers in Political Economy, 10(3), 1-62.

Chenery, H.B. (1975): The structuralist approach to development policy, in: American Economic Review, 65(2), 310-316.

Daly, H.E. (1991): Elements of environmental macroeconomics, in: Costanza, R. (ed.), Ecological Economics: The Science and Management of Sustainability, New York: Columbia University Press, 32-46.

Daly, H.E. (1996): Beyond Growth: The Economics of Sustainable Development, Boston: Beacon Press.

Dutt, A.K. (1999): Structuralist theory of development, in: O'Hara, P.A. (ed.), Encyclopedia of Political Economy, vol. 2, London: Routledge, 1118-1120.

Ekins, P., Folke, C., De Groot, R. (2003): Identifying critical natural capital, in: Ecological Economics, 44(2), 159-163.

Fontana, G. (2010): Money, Uncertainty and Time, London: Routledge.

Fontana, G., Sawyer, M. (2012): Towards Post Keynesian ecological macroeconomics, University of Leeds, mimeo.

Global Footprint Network (2013): Footprint basics - overview, URL: http://www.footprintnetwork. org/pt/index.php/GFN/page/footprint_basics_overview/ (accessed April 2013).

Kaldor, N. (1955): Alternative theories of income distribution, in: Review of Economic Studies, 23(2), 83-100. 
Pollin, R. (1995): Financial structures and egalitarian economic policy, in: International Papers in Political Economy, 2(3), 1-35.

Rosnick, D. (2013): Reduced work hours as a means of slowing climate change, in: Real-World Economics Review, 63(25), 124-133, URL: http://www.paecon.net/PAEReview/issue63/ rosnick63.pdf.

Sustainable Scale Project (2013): Ecological footprint, URL: http://www.sustainablescale.org/ conceptualframework/understandingscale/measuringscale/ecologicalfootprint.aspx (accessed May 2013).

Taylor, L. (2004): Reconstructing Macroeconomics, Cambridge, MA: Harvard University Press. Wackernagel, M., Rees, W. (1996): Our Ecological Footprint: Reducing Human Impact on the Earth, Gabriola Island, British Columbia: New Society Publishers. 